\title{
Persuasion or Manipulation: A Critical Discourse Study of Al-Aswany's Political Op-ed Post-Revolution Articles (2011-2014)
}

\author{
Mona A. S. AbdelFattah ${ }^{1,2}$ \\ ${ }^{1}$ Arab Academy for Maritime Science and Technology \\ ${ }^{2}$ Sadat Academy for Management Sciences
}

November 1, 2022

\begin{abstract}
The study is concerned with Al-Aswany's political opinion articles that have been published since 2011 until 2014 . The study investigates whether Al-Aswany persuades or manipulates the reader. Using VanDijk's model, presuppositions as well as the directives in Hyland's model of interaction, the study aims at analyzing how Al-Aswany manipulates the reader. Moreover, the study is set to find out whether a correlation between the use of directives and manipulation exists. The data used, in this study, are drawn from Al-Aswany's opinion articles that have been published in Al-Masry Al-Youm newspaper. The researcher has selected two articles from each year: 2011, 2012, 2013, and 2014.
\end{abstract}

\section{Introduction}

Dramatic changes have occurred in Egypt on various scales since the beginning of 25/1: political, economic, social, etc. These adjustments would have a significant effect on the people of Egypt. One of the revolution's main factors is that various views and values have been unleashed. When they openly share their various points of view, attitudes, values, and philosophies, people are no longer constrained. The media has made it easier to convey, shape and influence the point of view of the public. Ideologies have been replicated, reshaped, or at least inspired since the start of the first revolution. In sharing their thoughts, views, beliefs, even writers have had their share of freedom.

Alaa Al-Aswany is one of the most prominent writers who, at times, expressed their opinion on the political structures in Egypt clearly and very aggressively even before 25/1. He is well known for his novels in which the regime of Mubarak is criticized. Al-Aswany is a renowned Egyptian author and writer who experienced a time of corruption followed by two critical revolutions, respectively, 25/1 and 30/6, which had a significant effect on Egyptian society. Not only is he popular in Egypt for his writings, but in the Middle East as well. In addition, his work is being translated and published around the world in many languages. Within and outside Egypt, he is considered by many to be one of the most famous, influential novelists and writers in the region.

\section{Statement of the problem}

Many Egyptians experienced a great deal of instability, corruption, inequality, deprivation, persecution, and oppression during Mubarak's 30 years of presidency, culminating in the abruption of 25/1 in 2011. The nation has experienced different vital events from this point onward, including the second revolution on 30/6, 2013. Egyptians have witnessed many political leaders, regimes, activities, and incidents during which many views have been articulated. Al-Aswany is one of the most prominent, influential, and powerful voices that inspired many individuals during the period from 2011 until he stopped writing in 2014. 
The analysis is primarily concerned with Al- Aswany's opinion articles that were published right after the first revolution in 2011 in Al-Masry Al-Youm newspaper until he refrained from writing in 2014. As they portray Al- Aswany's views on what was then taking place, these articles are highly significant and crucial. It has significantly enhanced its effect on the reader by being printed in the press and, thus, accessible to the average citizen. In these articles, Al-Aswany expresses his attitude towards the two previously mentioned revolutions, the different political structures that existed before and after $25 / 1$, political figures such as Hosni Mubarak, former president of Egypt from October 1981 to February 2011, Mohamed Morsi, former president of Egypt from June 2012 to July 2013, as well as events and incidents that took place in Egypt since the onset of $25 / 1$.

The ease of access to his opinion posts, whether in print or online, has led to their widespread and, thus, their influence as they are likely to have a greater impact as the writer voices his opinion, views, thoughts, values, behaviors, and even ideologies in an engaging way to the reader. The reader or recipient is not only a receiver in any written or spoken conversation, but he/she has a role to play in receiving, recognizing, negotiating meaning, endorsing or refuting the proposed ideologies. This is what makes writing a type of social interaction. Therefore, the authors have to make a lot of effort and use different instruments to convey the message and influence their readers to embrace the argument posed.

\section{Research Objectives}

The purpose of the study is to examine whether there is an attempt to persuade or manipulate the reader.

\section{Research Questions}

The study aims at answering the following research questions:

1. Is the writer persuading or manipulating the reader?

2. How does Al-Aswany use presuppositions to manipulate the reader?

3. Is there a correlation between the use of directives and manipulation?

\section{Rational of the Study}

Taking this into account, one might argue that Al-Aswany can easily express his views to the reader in an interactive manner as a left antagonist writer who is immensely popular and as a novelist. In addition, Al-Aswany is a revolutionist who opposed the dictatorship of Mubarak even before 25/1 in his novels. He also participated in the revolution and during that time he had a lot of influence on his readers. Al-Aswany's writing style is worth learning as a revolutionist and a left opponent writing opinion columns. His pieces of political opinion writing focus on the political systems and historical events that took place after the first revolution. In this research paper, the articles selected cover important periods in Egyptian history. It is therefore very interesting to examine his articles because they echo one of the most prominent voices that was dominant during that period. Some of these incidents and events include the former post-revolution military rule, the presidential election, Morsi's election victory, June 30th, etc. These incidents and events are covered in the selected papers and analyzed using Van dijk's manipulation strategies including lexical derogation, selective accusation, presuppositions, disclaimers, positive self-presentation, suspicions and accusations as facts, generalizations, numbers game, etc.

In opinion articles published in newspapers, it is evident that the writer is not merely voicing his/her point of view, but, in fact, the writer is most likely influencing his/her addressee to approve the proposed argument and thus endorse it. Looking at the strategies that the writer implements to affect the reader is very insightful.

\section{Scope of the Study}

In 2011, after 25/1 and up until 2014, Al-Aswany kept writing weekly opinion articles. They were published in Al-Masry Al-Youm newspaper and posted on the newspaper's website. The research examines eight articles, two from each year (2011-2014). Since they follow significant events relating to the two revolutions, the selected articles are critical. They not only present an overview regarding the events, but also the opinion 
and comments of Al-Aswany about them. The papers were published in the press and on the newspaper's website, making them easily available up to this point.

\section{Significance of the Study}

In 2011 and 2013, the two revolutions had a profound influence on society as a whole and in numerous fields and disciplines. Language, whether written or spoken, is one of the essential fields to be explored in relation to revolutions. Language is a medium that expresses ideology and helps to reshape it at the same time. From the beginning of the first revolution until now, many talk shows have been produced and many newspaper articles have been written. By exporting their philosophies to the audience, many influential figures have attempted to persuade, manipulate and even twist the directions of the two revolutions.

The research tackles the mindset of one of Egypt and the Middle East's contemporary, most influential, popular, well-known authors. The writer not only expresses his ideologies and viewpoints to persuade the reader, but he also seeks to attentively manipulate him/her. By using a range of linguistic devices to present his case and engage his audience, the writer is able to manipulate the readers. In addition, no linguistic analysis has examined the papers selected and analyzed in this study, to the best knowledge of the researcher.

\section{Literature Review}

By an argument here I mean a set of one or more reasons for doing something, such as-but not limited to-to adopt or maintain an attitude such as a belief but also such as hope, or anger, or expectation; to accept a proposition; or to engage in an activity. (Blair, 2011)

Pinto (2010, p.30) draws a distinctive line between an argument and presenting an argument. Whereas the latter is concerned with "inviting" others through "advocating" an argument to accept its conclusion based on the reasons provided, the former merely states the reasons behind the argument.

By persuasion I mean the concept that is well analyzed by O'Keefe $(2002$, p. 5) as: ... a successful intentional effort at influencing another's mental state through communication in a circumstance in which the persuadee has some measure of freedom.

Since "mental state" here is meant broadly to include dispositions to act or decisions no less than propositional attitudes such as beliefs or commitments, I do not make a distinction between persuading to (do something) and convincing that (something is the case) (Blair, 2011).

In their definition, Seiter \& Gass state that "persuasion involves one or more persons who are engaged in the activity of creating, reinforcing, modifying or extinguishing beliefs, attitudes, intentions, motivations and/or behaviors within the constraints of a given communication context" (2003, p. 34). Persuasion can also be interpreted as exploiting one's available resource to change people's opinions and consequently their behavior.

The difference between persuasion and manipulation basically comes from the fact that persuasion includes the interlocutor's acceptance and consent. Manipulation, on the other hand, means that the exercise of this free will is hindered. if the latter becomes conscious of the goal that the manipulator is pursuing, it is no longer a case of manipulation, even if the manipulated party adopts the attitude or otherwise carries out the behavior sought by the manipulator (Nettel \& Roque, 2011).

Hart (2013), implementing two cognitive theories in psychology together with argumentation strategies, examines immigration-related media discourse. It is argued that persuasion and manipulation share the same goal which is influencing audience's views, judgement, actions and decisions (Hart, 2013; Reisigl and Wodak, 2001). However, two identified factors draw the difference between persuasion and manipulation. While the first is concerned with speech act's exploitation as an argument, the second focuses on the intention of the speaker that is the degree or amount of impact the speaker intends to cast on the audience's judgement, decision and/or actions. In fact, covertness is the key on which manipulation rests, hence, it is very difficult to unfold the speaker's intention. As a result, based on Maillat and Oswald's (2009) work, Hart argues that the major difference between the two is that the latter is depicted mainly from the audience's part. 
Hart's study concludes that in order for a manipulative act to succeed it works on the means by which the mechanisms controlling our information processing act.

Hart takes the notions of influence and persuasion to a higher level. In his study, he defines heuristics as schemes derived by which certain dilemmas are resolved. However, these schemes are usually "fallible" resulting in errors and biases on which manipulation thrives (Hart, 2013). Consequently, heuristics involving emotions can be considered a successful technique in steering actions and decisions (Cosmides and Tooby as cited by Hart, 2013). Consequently, pathetic fallacy is one of the discursive strategies that through arousing affect manipulation of hearer can occur.

Maillat and Oswald (2009), in their paper, discuss five different criteria by which researchers proposed a definition of manipulation: truth or felicity conditions, speaker interests, covertness, social inequality and intentions. The first criterion states that manipulation occurs when the manipulator uses false statements i.e. lying. In other words, manipulation occurs when Grice's maxim of quality is violated. However, Maillat and Oswald argue that this is not necessarily true. The logic behind their argument lies in the fact that manipulation does not always depend on lying since the manipulator could use sincere propositions with hidden intentions that the addressee is not aware of. In addition, not all false statements are intended for manipulation as shown in their example of Santa. Another dilemma with this method is what Parrett (1978) suggested stating that the use of speech act as a theoretical framework is not compatible since the principle of expressibility "I manipulate you + proposition" cannot be applied (as cited by Maillat and Oswald, 2009).

The second aspect, speaker's interest, is addressed. Maillat and Oswald proposed a question of whether a manipulative act could be used to serve the addressee's own interest. In their pursuit, Maillat and Oswald, giving the example of the sick friend with the injection phobia and contrary to Van Dike's belief regarding manipulation, argue that a manipulative act could be used to serve the speaker as well as the hearer's interests. That is to say a manipulative act could be implemented for the hearer's own advantage.

Thirdly, the issue of intention is addressed. They further argued that relying on identifying speaker's intentions is a very difficult approach since manipulation is directly related to covertness making it almost impossible to unfold since the whole idea behind manipulation is that the reader is not able to recognize that $\mathrm{s} /$ he has been manipulated.

The notion of covertness is also tackled. It is argued that in order to succeed manipulative acts have to be covert. The dilemma when focusing on covertness as the criteria by which manipulation is defined is the fact that it is controlled by various elements making it difficult to measure. The overall intention of the act, the discursive strategies, the linguistic strategies as well as the global strategies contribute act as variables when addressing the issue of covertness.

Finally, social inequality is another approach towards defining manipulation. Researchers claim that in order for manipulation to occur, "asymmetry between speaker and addressee(s)" has to be present. It is argued that manipulators abuse this "asymmetrical social conditions" resulting in an imbalanced relation of power and domination between speaker and hearer in which the speaker is placed at the top of the social hierarchy. The counter-argument suggested by Maillat and Oswald state that even though it is common for a person at a higher social position to manipulate someone at a lower place in the ladder of status, knowledge and so on, it is not uncommon for someone placed at a lower level to manipulate a person from a higher position, for example, professor-student, parent-child, etc.

In their defense, they introduce a Relevance theory-based framework as a new definition regarding manipulation focusing on the addressee's mental processing. Their study tackles how a manipulator uses words in a way that force the hearer into a "limited contextual selection" introducing the new definition stated below:

manipulation can be best defined in terms of the constraints it imposes on mental processing ... conditions affecting the reception of a manipulative message; specifically, we will define manipulation as a set of constraints limiting the processes of contextual selection. (Maillat \& Oswald, 2009, p. 361)

Based on Allott and Rubio Fernández's (2002) work, it is argued that certain lexical elements enable the 
hearer to create "cognitive shortcuts" by which shallow processing occurs, a phenomenon that reduces the effort on the hearer's part in interpreting the communicated message activating the "salient conceptual assumptions" accompanying a certain lexical item (as cited by Maillat \& Oswald, 2009).

Thus, opinion articles are influential tools that can be a threat. As a matter of fact, one can claim that it does not only influence and persuades the reader, but also, using the right strategies and techniques, it could be a tool for manipulation. However, more studies need to be done on opinion discourse implementing different approaches and theoretical frameworks to be able to state such a claim.

First of all, there is the text which aims at examining the text or discourse internal structure for selfcontradictions, problems, inconsistencies, and/ or paradoxes. Another is the "socio-diagnostic critique" which is based on the notion of "demystifying" since it aims at unveiling manipulative or persuasive aspects of a certain text. Finally, it aims at improving communication through future-related prospective critique.

Our analysis and discussion have revealed that although the discourse produced by Johnson Sirleaf to inspire the people in the task of national reconstruction appears to be geared towards achieving group cause, trappings of domination in the discourse cannot be mistaken. Cognitively, the way she skews the thinking of the people in the direction of the positive in spite of the stark realities of the ruins of war that stare the people in the face is interesting. So, in a bid to make the audience form a mental picture of the world painted by the rhetor, restrictions are inexorably placed on their freedom of interpretation, thereby suggesting that the world is understood only in terms of what the manipulator feels, thinks and desires. the manipulative rhetoric, as our analysis and discussion have shown, fits in perfectly into the predictable four-part pattern of the 'Pep Talk' of any cause group: the threat, the bonding, the cause and the response. While invoking the threat variable, JohnsonSirleaf intensifies the problems of the Liberian society but then appeals to the bonding factor by assuring the people that no matter the threats, the people's ability to stay united and be loyal and have pride would see them through. She appeals to the cause variable by evoking a sense of duty in the audience and finally the response variable finds expression in her identifying specific actions to be taken by using urgency pleas. (ADEYEMI ADEGOJU, 2013).

Another influential tool that could be used to influence reader's mind, thoughts, and ideology is the use of presuppositions. Since presuppositions are not only acknowledged or displayed, i.e. "covert" in nature, which enables the speaker to implicitly transmit different values for various aspects and at the same time does not give a room for criticism, they play a crucial role in influencing public opinions (Degano, 2007).

Degano (2007) concludes that although both types of presuppositions are present, affective presuppositions could be used, as a suggestion for future research, to study ideologies. As for epistemic presuppositions, however, interesting results have been yielded. The results of the study have shown that this type of presuppositions has been used in the press to refer to "weapons of mass destruction" in a way that presented the issue of illegal weapon possession by Iraq as taken for granted forcing this argument to move from an explicit to a more implicit level making it difficult to argue against or criticize the issue. The study claims that corpus linguistics could become a very useful tool if combined with CDA and argumentation theory to form a model for analyzing discourse structure.

The study combines various theoretical and methodological approaches to relate argumentation with critical discourse analysis and corpus linguistics. The study examines the way the British press have used presuppositions and dissociations in preparation for the war on Iraq. Both affective and epistemic types of presuppositions are examined. The latter, presented in the corpus, is composed of two groups. The first group is concerned with presenting allegations as evidence while the other with presenting opinions and judgments as "shared knowledge" (Degano, 2007).

It is possible to find cases of argumentation without persuasion, just as there are cases of persuasion without argumentation. This paper focuses on the overlapping territory, which we propose to call persuasive argumentation. To summarize the preceding, we can define persuasive argumentation as the communicational process by which a persuader seeks to put the persuadee in a favorable disposition that leads the latter to commit to an action presented as desirable. This disposition is obtained by a freely consented acceptance 
that should lead to a change in behavior. The acceptance results from the examination of the reasons given by the persuader, among which emotions can also play a role (Nettel and Roque, 2011).

An analysis of news headlines and editorials of Globo has shown that the newspaper systematically manipulated its readers, public opinion and politicians in order to promote and legitimate a coup as a constitutionallybased impeachment of Dilma Rousseff. It did so not only by extensive daily reports and editorials about the alleged criminal conduct of Dilma, Lula and the PT, but also through many different discursive strategies, such as presenting accusations as facts, celebrating and legitimating the anti-PT judge Moro, populist coverage of demonstrations, disclaimers, numbers game rhetoric, positive self-presentation, and attacking the accusation that the impeachment was in fact a political coup. By omitting information about the expert opinions of legal scholars or of the international press, for example about the grounds for impeachment, the newspaper is not merely politically biased but engages in serious misinformation. the newspaper becomes the mouthpiece of an ideological conspiracy of the conservative oligarchy to return to political power after 13 years, thereby confirming and continuing its economic power. Because of Globo's near monopoly of TV news, millions of Brazilians have little access to alternative, more balanced information. Our corpus consists of the 18 editorials on Dilma, Lula, the PT and impeachment published in the Globo newspaper during the months of March and April 2016, strategically preceding the decision of the Câmara de Deputados to initiate the impeachment procedure against the president. The editorials accompany thousands of news articles in both Globo and the other conservative media, systematically presenting a grotesquely biased form of disinformation about Lula, Dilma and the PT. The editorials have been chosen as the target of this article because they explicitly formulate the opinions of the newspaper. We shall also briefly examine the headlines of the front page news articles about them, because this information is often presupposed in the editorials (a complete analysis of the epistemics of presupposed information in editorials would be an interesting topic of study. the editorials begin to be manipulative when their assertions or presuppositions of the facts are biased or false in ways readers cannot or will not readily check, because in that case we witness partisan and systematic epistemic control of the readers' mental models. Related to this point is that the news reports and editorials hardly pay attention to the legal arguments of many experts against the impeachment. Failing to provide this information is undoubtedly a form of manipulative knowledge management (omission of information). He noticed that the manipulative discourse worked on several aspects: lexical derogation, selective accusations, presuppositions, disclaimers, positive self-presentation, suspicions and accusations as facts, generalizations, numbers game, legitimation of impeachment and delegitimization of the accusation of a coup. (T. A. Dijk, 2017).

The results of the analysis of manipulation in the Rajoy-Rubalcaba and Obama-McCain debates reveal similarities and differences in the use of manipulation. In general terms, the Spanish candidates used more manipulation than the Americans in the same debate time and favored fallacies over any other manipulative process, followed by falsities and insincerities, while the results are more balanced for the American candidates. No doubt, fallacies are preferred because they serve well the purpose of appearing to present a rational argument while, in fact, being deceptive moves designed to influence the result of the discussion to the candidates' own advantage (Cabrejas-Peñuelas, 2015).

The most frequent strategies which are used in Tehran Times' report are lexicalization and repetition. These two strategies, along with other strategies of vagueness and polarization, are used to give a positive image of the reaction of Russia towards Iran. Similarly, in The Los Angeles Times' report, lexicalization is the most frequent strategy which is used by the writer to give a negative image of the reaction of Russia towards Iran after the speech. The results obtained from the CDA analyses of the news reports showed that ideological manipulations of language can be realized by the deployment of the two general semantic macro-strategies of Van Dijk's (2000) framework: positive self-presentation and negative other- presentation which are manifested by other discursive strategies within this framework (Farahani and Moussa, 2014).

In his study, Hyland creates an interaction model that combines both stance and engagement features. Stance is how writers choose to express their judgments, opinions and commitments. Engagement is concerned with how writer's regard reader's as "discourse participants" being aware of their presence and leading them to 
certain interpretations. Directives ask reader to perform an action or share the writer's perspective on an issue. There are three types of acts in directives: Textual, physical, or cognitive. The first act refers the reader to another part of the text or another text. The physical act requires the reader to perform a certain action in the real world or a certain step in a scientific process. The third is the cognitive act. According to Hyland (2002a, 2005), cognitive acts are the "most threatening" acts since they guide the reader to a certain argument or conclusion and enables the reader to view a certain perspective intended by the reader in order to "get them to understand a point in a certain way". One could argue that, taking into consideration Hyland's definition of cognitive directives, there might be a direct relation between the use of directives and manipulation.

\section{Methodology}

\section{Data and Data Collection Procedure}

The data used, in this study, are drawn from Al-Aswany's opinion articles that have been published in AlMasry Al-Youm newspaper. The data are selected from many articles written by the author and posted on the newspaper's website. The researcher has selected two articles from each year: 2011, 2012, 2013 , and 2014. The selected articles are crucial since they follow important events related to the revolutions. Some of these incidents and events include the former military's rule after the revolution, the election for presidency, Morsi's winning of election, $30^{\text {th }}$ of June, etc. These incidents and events are covered in the selected articles below. All in all, eight selected articles are gathered for analysis. The following chronologically ordered articles will be analyzed using the various linguistic tools mentioned earlier:

"mdh ntwq' mn lmjls l'skry. . . ?" maadha natawaqac min almagles alcaskarii

"What should we expect from the Military Council. ..?" (21/6/2011)

'kyf tqDy 'l lthwr@ fy st khTwtkaifa taqDii calaa althawra fii sit KHaTawaat

"How to eliminate the revolution in six steps?" (2/8/2011)

"qbl 'n tdly bSwtk fy l'd@" qabla ?an tudlii beSawtika fii al?iicadaa

"Before you vote in the re-run" (4/6/2012)

lmdh fz mrsy?" limaadhaa faaza mursii

"Why did Morsi win?" (25/6/2012)

"mlHZt 'l msr lthwr@" mulaHazaat cala masaar al thawra

"Explicit Remarks on the Path of the Revolution" (29/7/2013(

"hl nwfq 'l ldstwr?" hal nuwafiq cala al dustuur

"Should we accept the constitution?" (16/12/2013)

"hl ybHth lmSrywn 'n 'b?" hal yabHath al misryuun can ?ab

"Are the Egyptians looking for a father?" (27/1/2014)

mdh t'rf 'n mrD lkrsy? !' madhaa tacrif can maraD al kursii

"What do you Know about the Chair (authority) Disease?" (1/4/2014)

\section{Approach}

In its quest, the study adopts a qualitative analysis method as it sets DHA as a conceptual framework that provides the background or context in which the opinion articles emerged and, hence, analyzed. Some of these incidents and events include the former military's rule after the revolution, the election for presidency, Morsi's winning of election, $30^{\text {th }}$ of June, etc. These incidents and events are covered in the selected articles mentioned earlier. Moreover, DHA works with various linguistic tools. DHA has numerous discursive 
strategies. However, the study focuses on argumentation. The study uses argumentation and presuppositions, not to examine the writer's ideology per se, but to examine the level of persuasion and whether there is an obvious manipulation from Al-Aswany's part.

Not only does the study focus on Al-Aswany's level of persuasion, but also the strategies employed to manipulate his readers. Moreover, the study uses the directives in Hyland's (2005) model of interaction to examine how the writer engages the reader and persuades him since Hyland (2002 \& 2005) discuss how cognitive directives are considered a huge form of threat as it plays with the reader's mind. Finally, the study also uses Van Dijk's (2017) study as a model to study manipulation techniques. The research also examines the use of directives in Hyland's model of interaction. Therefore, the study uses eclectic tools to provide reliability and, hence, validity of the analysis and results.

\section{Analysis of the Study}

\section{Lexical Derogation}

As shown in Table 1, the analysis shows how the writer explicitly establishes an opposing stance throughout the examined texts since the attitude markers as well as the lexical items associated with Mubarak and his regime are all negative. The use of phrases like shrt mqlq@/ish ārāt muqliqah/alarming signs and mkhwf mshrw'@/makhāwif mashrū'ah/legitimate concerns expresses the writer's fear of the return of Mubarak's regime. Other negative lexical items appear frequently in the text to describe the regime such as $f_{s d} / f_{a s i d}$ / corrupt , stbddy /istibdāa / totalitarian and $q m^{\prime} y / q a m^{\prime \prime} \bar{\imath} /$ oppressive. In addition, negative attributes describing Mubarak are depicted such as khy'n /khā in/traitor ,'myl /'amil/agent, dykttwr /diktätür/ dictatorandZlm unfair /ālim/. The beneficiaries as well as the police, as shown in Table 4, are always related to and presented as part of Mubarak's regime, hence sharing the same negative qualities. Lexical items indicating theft is always present with the former, for example, 'Sbt/'iābät/gangs, llSwS /al-liū/ thieves and $n h b / n a h b /$ plunder while lexical items related to torture and inhumane acts are associated with

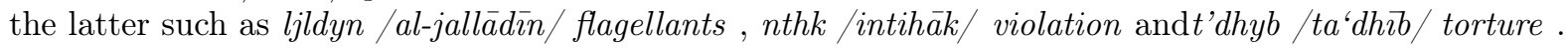

As can be seen in Table 1, different lexical items are attributed to the army and the Former Military Council. The analysis shows that the writer distinguishes and treats both entities separately. The latter is mostly presented as the supporter of Mubarak's regime whereas the former is the savior of the revolution. This is apparent in the use of lexical items like l'Zym /al-'aìm/ the great, qrr shj' /qarār shuga'/ bold decision, m'rwf /ma'rüf/ well-known and mqdr/muqaar/ appreciated. As a matter of fact, the research depicts writer's use of the word jysh /jayish/army when he speaks positively about it. However, on the other hand, when the writer chooses to criticize the military institution he calls it lmjls l'skry/al-majlis al-'askarī/ the military council or lmjls l'skry lsbq /al-majlis al'askarì al-säbiq/ the former military council attributing negative lexical items such as mkhTT / mukhaa/scheme, jhD /ijhä/termination , trwy' /tarwi “/ terrorizing,mdhbH /madhäbi/massacre and tshwyh/tashwih/disfiguring .

\section{Table 1}

Lexical Items Associated with the Main Entities

\begin{tabular}{ll}
\hline Entity & Lexical Items \\
\hline Mubarak and his Regime & lqdymthe old, fsd corrupt, stbddy totalitarian, l'Sr lby'd the old era, qm'y@ oppressive, dkttwr \\
The beneficiaries & flwl, llSwS thieves, 'Sbt gangs, wjwh qbyH@ ugly faces, nhb plunder, qm' oppression, mzr'@ \\
Police & lfsdynthe corrupted, ljldyn/-wn flagellants, qtl@ killers, nthk violation, t'dhyb torture, hdr krm \\
The Army & l'Zym the great, nHzw llthwr@ they sided with the revolution, rfDw Tlq lnr they refused to sho \\
Former Military Council & mw'ss@ institution, mHfZ@ conservative, Gyr thwry@ unrevolutionary, mnDbT@ regimental, T \\
The Brotherhood & Ty'f@ dyny@ religious sect,fshy@ fascists, Dl@ aberrant, tHryD instigation, 'nf violence, t'dhy \\
$25 / 1$ & Htrm respect, krm@ dignity, freedom Hry@, 'Zym@ great, mtfrd@ unique, ltGyyrchange, dym \\
$30 / 6$ & ntfD@ sh'by@ kbr a major popular uprising, mtdd lthwr@ extension of the revolution, frS@ dh \\
\hline
\end{tabular}




\section{Selective Accusations}

Al-Aswany explicity states accusations regarding certain incidents. For example, in Table 2, Al-Aswany questions the reliability and validity of the elections. He does not only questions but also throws explicit and direct accusations using lexical items like mzwr@ forged. He also explicitly points finger at the judging system and the corruption of judges as he uses the lexical items lqDy lfsd the corrupted judge. Moreover, he straightforwardly labels police officers as ljld the whipper. Lexical items associated with police officers are all negative like y'dhb tortures and yqtl kills. Al-Aswany explicitly accuses Mubarak's regime stating that it is trying to abort 25/1 as he says w qd nfdh nZm mbrk mkhTT dqyq ljhD lthwr@w'd@ 'Sbt mbrk llslT@Mubarak's regime implemented a precise plan to abort the revolution and restore Mubarak's gangs to power. Al-Aswany highlights some accusations regarding the Shafik vs. Morsi presidential elections as he uses lexical items likeshbth marred, tzwyr fraud and to confirm this he uses the words msjl@ recorded and mwthq@documented in the following example nlntkhbt lry'sy@shbthwqy"tzwyr'dyd@klh msjl@wmwthq@ bd mn tSwyt lmtwfyn l tSwyt l'skryyn lSlH shfyq blmkhlf@llqnwn ldh ymn'hm mn ltSwyt The presidential elections were marred by many fraud incidents, all of which are recorded and documented, starting with the votes of the deceased to the votes of the military in favor of Shafiq, in violation of the law that prevents them from voting.

Table 2

Examples of Selective Accusations

Examples of Selective Accusations

lmjls lmHly@ wtHdt l'ml lt jt bntkhbt mzwr@ wshtrk kthyrwn mn qydyyh f jry'm lnZm lsbq, trkh lmjls l'skr km

\section{Presuppositions}

presuppositions are inferences or propositions, formed by the use of lexical items and linguistic constructions named as presupposition triggers, which make them taken for granted as an undebatable fact in a sentence or utterance. The findings of the study show that there are a lot of lexical items that play the role of presupposition triggers in Al-Aswany's articles. The study focuses on three main types of presuppositions, presented in Table 4.5, that frequently occur in the analysis: cognitive factives, aspectual/change of state predicates and iteratives.

\subsubsection{Cognitive Factives}

Table 4.5 shows the use of lexical presupposition triggers that indicate a cognitive process or task like t'rf /ta'rif/ you know ,ntdhkr /natadhakkar/ remember (we), nns /nansá/forget(we), ydrk/yudrik/ realize , nktshf /naktashif/discover (we) and y'lm /ya'lam/ he knows . Lexical items related to knowledge such as 'rf /'arifa/knew and 'lm /'alima/ knew are usually associated with corruption in general and that of the regime in particular as in sentences (1), (4), (5) and (12). Another cognitive task related to recalling is found in the analysis like $n t d h k r$ /natadhakar/andnns /nansá/ in sentences (6), (10) and (11). These lexical items are used to present a proposition as factual. In addition, the use of cognitive lexical items attributed to realization is also found in the analysis such as ydrk/yudrik/and nktshf / naktashif /in sentences (7), (8) and (9) which presupposes that people might not have been aware of what is going on at the beginning or that there is some sort of a scheme present.

\subsubsection{Aspectual/Change of State Predicate}

In Table 4.5, most of the lexical items used depict the country's state after the revolution as idle, presupposing otherwise before the revolution, which is considered a negative aspect. The analysis shows the use of lexical items likewqf lHl / waqf al-äl/ / halt of the economic situation and twqft/tawaqafat/ ceased in sentences (14) and (16). Other lexical items presuppose that an ongoing process or movement is still taking place mainly acts related to the corruption or oppression of the regime. To illustrate, lexical items such as $l G / i l g h \bar{a} /$ 
cancelling, mn'/man'/ prohibiting, Glq/ighlāq/shutting down and frj/ifräg/releasing are found in the analysis. For example, in sentence (13), in Table 4.5, the lexical item $l G / i l g h \bar{a}$ / cancelling hints at the fact that the law is still existing which is considered a sign of oppression. The lexical item lfrj / al-ifräg / releasing presupposes that there are still political prisoners. In Table 4.5, lexical itemslGlq /al-ighlāq/ shutting down and $m n^{\prime} / \mathrm{man}^{\prime} /$ ceasing in sentence (20) presuppose the State Security Service still exists, which is a sign of oppression, and people are still being oppressed as he says $m n^{\prime} / \mathrm{man}^{\prime} /$ cease ,qm' $/ q^{\prime} m^{\prime} /$ repress . The findings of the study highlight that the lexical items $m n^{\prime} / \mathrm{man}^{\prime} /$ and $t m n^{\prime} /$ tamna'/to cease, have occurred eight times. In sentences (19), (21) and (24), these lexical items presuppose that there is a great chance the old regime will get back, and civilians are judged by the Military Court which again is a sign of oppression. Such lexical presupposition triggers do not shed light on Mubarak and the former Military council's regime only, but also the corruption of the Brotherhood as well. For example, in sentences (22) and (23), Al-Aswany hints at the presence of corruption related to religious political parties, mainly the Brotherhood. Moreover, the lexical item $y q T^{\prime} /$ yaqa $^{\prime}$ / end in sentence (26) presupposes that the relationship between Morsi and the Brotherhood is still going on even though he promised otherwise.

\subsubsection{Iteratives}

This type of presuppositions is the most frequently used compared to other types. As shown in Table 4.5, there are two sub-types of iteratives: verbs and lexis. Iterative verbs like $y^{\prime} w d w / y a^{6} \bar{u} d \bar{u} /$ they returned, ' $d t$ /'ädat/ returned, st'd /ista'āda/ retrieved, 'd/'àda/returned and 'd@/i'ādah/ re-doing which come from the verb ' w d meaning to return, appear frequently in the data, as shown in examples from 28-57 in Table 4.5 , which presupposes that the old regime, corruption, and oppression were present before. Lexical items and phrases associated with this verb areldwl@lqm'y@/al-dawla al-qam‘'iyah/the repressive state, dwl@ mbrk /dawlat mubārak/ Mubarak's state, lt'dhyb /ta'dhib/torture, 'Sbt mbrk/'iābāt mubärak/ Mubarak's gang, nZm mbrk lfsd/nidhām mubārak al-fäsid/ Mubarak's corrupted regime, DbT 'mn ldwl@/ubāt amn al-dawlah/ state security officersand lTwry' qnwn /qānūn al-awari/ emergency law. Also, the author uses the verbykrr/yukarir/ and $n k r r$ /nukarir/ from the verb $\mathrm{k} \mathrm{r} \mathrm{r}$ which means to repeat, indicating that mistakes have occurred before. Unlike the verb ' $\mathrm{w} d$ which occurs with the old regime, the verb $\mathrm{k} \mathrm{r} \mathrm{r}$ is only associated with this group showing that these people work on serving their own hidden agendas playing with the same cards. The second sub-type also appears frequently in the data as shown in Table 4.5. The phrases (x7) mn jdyd / min jadìd / and (x3) mr@ 'khr /marra ukhrá /, which meanagain, highlight that nothing has changed since the revolution. Also, the word jdyd/@ /jadìd-ah/ and jdyd /jadīdan/ meaning newhas occurred twenty-two times in the data. According to the data presented in Table 4.5, these lexical items are usually associated with the following words: fshy@/fāshīyah/fascism, nZm /niām/regim, dstwr /dustür/ constitution and dkttwry@/diktätüriyah / dictatorship presupposing that there was an old constitution, an old regime, an old fascism and a previous dictator. The word fshy@/fäshīyah / fascism refers mainly to the Brotherhood; however, Al-Aswany is warning the reader of creating a new fascism in El-Sisi's era. Moreover, the lexical item jdyd/@/jadìd-ah/new appears with two figures: 'bdlnSrAbdelNasser and fr'wn The Pharoah hinting at the notion of history repeats itself which is another warning. The use of the lexical item'khr /ukhrá/ meaning another in jrym@ 'khr/jarima ukhrá / another crime referring to the Brotherhood also presupposes that there was a previous incident as in example 72 in Table 4.5. The lexical item $\mathrm{mrr} /$ miraran/repeatedly and the lexical phrase $\mathrm{mrr} w \mathrm{tkrr} /$ miraran wa tikraran/ over and over have occurred in the data three times also presupposing repetition of events. The latter expression is associated with the Former Military Council and the Brotherhood presupposing that rules have been violated several times before. The former presupposes that the Egyptian people have suffered before several times.

Table 3

Three Main Types of Lexical Presupposition Triggers

Types of Presuppositions $\quad$ Examples

Factive predicates:

Aspectual/change of state predicates:

Epistemic/cognitive factives: ('nt t'rf 'n lmkhlw' kn khy'n w'myl l'kthr mn jhz mkh

(13) yjb 'lyh lG qnwn ltZhr wlfrj fwr 'n lm'tqlyn ldhyn lm yrtkbw jry'm l'n njHh k 


\begin{tabular}{ll}
\hline Types of Presuppositions & Examples \\
\hline Iteratives: & Iterative verbs: (28) 'jm' fqh lqnwn ldstwr 'l 'n ldstwr lqdym qd sqT bsqwT lnZm \\
\hline
\end{tabular}

\section{Disclaimers}

Positive Self-presentation vs. Negative Other-presentation

Table 4

Positive Self-presentation vs. Negative Other-presentation in Al-Aswany's Political Artices

Us

1. Al-Aswany qrr kthyrwn - w'n mnhm - mqT'@ lntkhbt, 'trD 'l wjwd shfyq bdl mn 'zlh wmHkmth. lknn lm 'wfq 'l lT

2. Revolutionists bdan mn tshwyh lthwr wthmhm bl'ml@, thm sthdf shbb mSr bmdhbH bsh'@ tm khllh qtl my't lmwTn

3. People yjb 'n tDGT 'l lns l'dyyn Ht y'wdw l mq'd lmtfrjyn.. yjb 'n ttfqm l'zmt f kl mkn. lflHwn yjb 'n tnqT' 'nhm

4. The Army lnhm Hsw n jyshhm yHmyhm Dd... whw ljysh lmSr ldh mhm khtlfn m'h yjb 'l nns ... dwr ljysh f Hmy

\section{Suspicions and Accusations as Facts}

Table 5

Examples of Suspicions and Accusations as Facts

Examples of Suspicions and Accusations as fact

lHq 'n lstft dhth kn nzyh wGyr mzwr lkn b’D lmmrst lkhTy'@ Hdtht qbl lstft w'thrt bl shk f ntyjth. lHtfZ bmsw'wlyn kth

\section{Generalizations}

Table 6

Examples of Generalizations

Examples of Generalizations

lkn lmSryyn lan yHswn bqlq wtwjs mn lmstqbl. lHtfZ bmsw'wlyn kthyryn mn lnZm lqdym $\mathrm{f}$ mnSbhm...

\section{Numbers Games}

Table 7

Examples of Numbers Games

mzlt 'dhkr ywm 25 ynyr 'ndm wSl alf lmtZhryn mn mbb@ lynDmw l mydn ltHryr. blDf@ 1 alf lmSbyn, k

Legitimation of the two revolutions

Table 8 
Examples of Legitimation of the two revolutions

$l s h ' b l b T l$ lHqyq fym Hdth ywm l'Hd lmD 24 ywnyw. dhlk ltrykh ldh yshkl nqT@ frq@ f trykh mSr wl'lm

Delegitimizing certain actions and decisions

Table 9

Examples of Delegitimizing certain actions and decisions

'l md 16 shhr nfdh lmjls l'skr mkhTT m'dan b'ny@mn'jl jhD lthwr@lmSry@: nflt 'mn wHwdth Ty'fy

Populist Strategy: The People

Table 10

Examples of the Populist Strategy

mlyyn lmSryyn ldhyn nzlw l lshwr' lywjhw lmwt knw yntSrwn llkrm@wlHry@, kl wHd fyhm kn 'l st'dd l'n

\section{Directives}

The analysis of the study shows that directives are the most frequently used feature comprising $38 \%$. As a matter of fact, the cognitive act, based on the findings of the study, is the only type of directives used (see Table A1). Accordingly, as mentioned in Chapter Two, Al-Aswany uses the most dangerous type of acts. In fact, the analysis depicts the use of:

imperative verbs like tkhyl/takhayyal/imagine, ftrD /iftari/assume, Df l /aif ilá/ add to as stated in examples (45) and (47).

(45) tkhyl nk t'ml fy wZyf@ mmtz@...

Imagine you have an excellent job ...

(46) ftrD b'd dhlk 'n Hryqan qd shb f ldwr ldh tsknh...

Then, suppose that a fire broke out on the floor where you live ...

(47) 'Df $l$ dhlk jhz ldwl@ blkml, ldh snd shfyq bkl qwth...

Add to this, the entire state which has supported Shafiq with all its might...

verbs indicating obligation, which are close to the modal verbs in English, like yjb 'n /yajib an/must/should (occurring 33 times) and ' $l+h+$ 'n must and phrases like $m n+1+$ 'n/lmSdrsuch as mn $l S ' b /$ mina al-a'bi/ it is difficult to, mn lshl it is easy to /mina al-sahli/, mn lDrwry ' $n$ it is necessary to /mina al-arürì an/ as shown in examples (48) to (50).

(48) fnn $y j b$ 'n nwfq 'l hdh ldstwr l'n rfDh stkwn lh 'wqb 'sw' bkthyr mn lmHkmt l'skry@ llmdnyyn.

we must agree on this constitution because rejecting it would have far worse consequences than the military trials of civilians.

(49) f wsT hdh lmshhd lDbb 'zyz lqry' wqbl 'n tdl bSwtk f ntkhbt l'd@ 'lyn 'n ntdhkr b'D lHqy'q...

Amidst this blurry scene, dear reader, and before you cast your vote in the runoff elections, we must remember some facts:

(50) thm twl lkhwn lHkm fzddt l'mwr sw, w'Hs lns b'n lbld qd wq' f 'yd 'frd 'Sb@ mn lS'b st'dth mnhm. 
Then the Brotherhood took over, so matters got worse, and people felt that the country has fallen in the hands of gang members which made it difficult to retrieve.

negation as a means of directing the reader using the words of negation such as $l /$ lā/ no and lys /layisa/not as shown in example (51).

(51) 30 ywnyw lyst thwr@ mnfSl@ 'm sbqh, l'n lthwrt $l$ tSn' kl 'myn, km 'n mZhrt lywm lwHd (mhm kn Hjmh kbyr)l ymkn 'n tsm thwr@.

June 30 is not a separate revolution from what preceded it because revolutions are not made every two years, and one-day demonstrations (no matter how large they are) cannot be called a revolution.

Cognitive verbs indicating the reader's state of mind, for example,nktshf /naktashif/ we discover , fwjy'n /füjinā/ we were surprised and ntwq'/natawaqa'/ we expect. Sentences (52) to (54) indicate this notion.

(52)whn nktshf 'n l'khT lqnwny@ tHyT blljn@ l'ly mn kl jnb..

And here, we discover that legal violations surround the Supreme Committee from every side.

(53) l hn wl'mr Tby' yHdth f ' bld dymqrT, lknn fwjy'nbtHwyl l'stdh hykl l lnyb@ l'skry@.

Until here, it is a normal situation that can happens in any democratic country, but we were surprised that Mr. Heikal was referred to Military Prosecution.

(54) nHn hn ntwq' mn lmjls l'skr 'n ystm' l lar jmy' wytkhdh mn lkhTwt m yDmn 'dm syTr@ fryq sys b'ynh 'l ldstwr lqdm.

Here, we expect the military council to listen to all opinions and take steps to ensure that no particular political group imposes their control over the next constitution.

lexical items like bd /abadan/ever, fwr /fawran / immediately, wjb/wjbn/wājib/and /wājibunā/duty/our duty, $T b^{\prime} / b l T b^{\prime} / b^{2} a b^{\prime} /$ and /ab'an/ of course as illustrated in examples (55) to (58).

(55) n ldhyn y'Twn 'nfshm lHq f Hrq lkny's wzl@ l'DrH@ wtdmyr ltmthyl wthm mn ykhlfwnhm f lr' bl'd llslm wlkfr l ymkn 'bdan 'n ytfhmw ldymqrTy@ 'w yHtrmwh.

Those who give themselves the right to burn churches, remove shrines, destroy statues and accuse those who disagree with their views of being hostile to Islam and atheists can never understand or respect democracy.

(56) n wjb lry'ys mrs 'n ybd' fwr f tHqyq lqSS l'dl mn qtl@ lshhd wr'y@ 'srhm w'lj lmSbyn 'l "l mstw dkhl mSr 'w khrjh 'l nfq@ ldwl@.

The duty of President Morsi is to immediately start implementing a just retribution against the murderers of the martyrs, taking care of their families and treating the injured in the best way possible inside or outside Egypt at the state's expense.

(57) n wjbn lwTn ylzmn jmy' bd'm jyshn bkl qw@ f Hrbh 'l lrhb...

Our national duty obligates all of us to support our army with full force in its war on terrorism ...

(58) Tb'an stHwl 'n tHl lmshkl@ blHsn, lkn ljr lmz'j ytmd f l'td 'l Hqwqk...

Of course, you will try to solve the problem in a decent manner, but the annoying neighbor continues to violate your rights...

Based on the analysis of the study, directives are not restricted to single words or phrases, but also includes entire paragraphs. Three out of eight articles start with hypothetical situations requesting a mental act from the reader as illustrated in the following example.

(59) 'zyz lqry', tkhyl 'nk t'ml f wZyf@ mmtz@ brtb kbyr yHlm bh lkthyrwn, lkn lmshkl@ 'n ry'ysk f l'ml shkhS mtGTrs l ytwqf 'n hntk Twl lnhr... 'mmk dhn khtyr mn thnyn : m 'n trfD lhn@ wtntSr lkrmtk, wf hdhh 1Hl@ stkhsr lrtb lkbyr wtfqd 'mlk wtSbH f lshr', wlkhtyr lthn hw 'n tHwl lt'ysh m' lhn@ wttHml 
ldhll lknk stn'm lrtbwlHy@lrGd@...lkhtyr l'wlldh yrfD lhn@ wytmsk blkrm@, bGD lnZr 'n lnty'j, hw m yj'lk thwry... lthwr@ h 'n tfDl lm'n 'l lmSlH@, 'n tqdm lmbd' 'l lmnf'@.. lthwr@ h 'n trfD kl m yqyd nsnytk... hdh blDbT m Hdth f thwr@ mSr

Dear reader, imagine that you have an excellent job with a large salary that many dream of, but the problem is that your boss is an arrogant person who does not stop insulting you throughout the day... You have one of two choices: either you refuse the insult and triumph for your dignity. In this case, you will lose the big salary, your job and live on the street; meanwhile, the second choice is to try to cope with the insult and endure the humiliation while enjoying the salary and the good life... The first choice that refuses the insult and clings to dignity, regardless of the results, is what makes you a revolutionary... The revolution means that you prefer the meaning over the interest; in other words, choose the principle over the benefits. The revolution is to reject all What restricts your humanity... This is exactly what happened in the Egyptian revolution

As can be seen in example (59), Al-Aswany starts the article entitledmdh ntwq' mn lmjls l'skry? /mādhā natawaqa' min al-majlis al-'askarī/ What do we expect from the military council? by directly addressing the reader asking him to perform a cognitive task using the imperative verb tkhyl/takhayyal/imagine. In this hypothetical situation as well as the others, not only does he impose a certain imaginary situation on the reader, but also, he offers him/her solutions indicated by using mmk khtyr mn thnyn /amāmaka ikhtiyār min ithnayn/ you are faced with one of the following optionsand $m$ ' $n$ /imma an/ either leading him/her to a certain chosen answer imposed again by Al-Aswany as he says lkhtyr l'wl...hw m yj'lk thwry /al-ikhtiyär al-awwal... huwa mā yag'aluka thawriyan/ the first... is what makes you a revolutionist. In fact, according to the findings of the study, all the hypothetical situations follow the same pattern that is first requesting the reader to perform a mental task then provide certain limited logical choices followed by Al-Aswany's best selection from his point of view.

\section{Presuppositions}

\section{References}

Seiter, R. H. \& Gass, G. S. (2003). Persuasion, social influence, and compliance gaining (2 ${ }^{\text {nd }}$ Ed.). Boston: Allyn \& Bacon

Dafouz-Milne, E. (2008). The pragmatic role of textual and interpersonal metadiscourse markers in the construction and attainment of persuasion: A cross-linguistic study of newspaper discourse. Journal of Pragmatics , 40, 95-113.

Moghadam, F. D. (2017). Persuasion in Journalism: A Study of Metadiscourse in Texts by Native Speakers of English and Iranian EFL Writers. Theory and Practice in Language Studies, 7 (6), 483-495.

Hyland, K., \& Jiang, F. K. (2016). "We must conclude that...": A diachronic Study of Academic Engagement. Journal of English for Academic Purposes , 24, 29-42.

Boshrabadi, A. M., Biria, R., \& Zavari, Z. (2014). A cross cultural analysis of textual and interpersonal metadiscourse markers: The case of economic articles in English and Persian newspapers. Advances in Language and Literary Studies, 5(2), 59-66.

Pinto, R.C. 2010. The use of argument in communicative contexts.Argumentation, 24 (2): 227-252.

O'Keefe, D.J. 2002. Persuasion: Theory and research, 2nd ed. Thousand Oaks: Sage Publications.

Blair, J. A. (2011). Argumentation as rational persuasion. Argumentation, 26 (1), 71-81.

Cabrejas-Peñuelas, A. B. (2015). Manipulation in Spanish and American pre-election political debates: The Rajoy-Rubalcaba vs. Obama-McCain debates. Intercultural Pragmatics , 12 (4), 515-546. 
Adegoju, A. (2013). Manipulative Rhetoric and Post-war Reconstruction in President Johnson-Sirleaf's First Inaugural Address. 3L: Language, Linguistics, Literature @ 19 (1).

Nettel, A. L., \& Roque, G. (2012). Persuasive argumentation versus manipulation. Argumentation , 26 (1), $55-69$.

Farahani, E., \& Ahmadian, M. (2014). What is the truth? A demonstration of language manipulation in two newspapers and the pedagogical implications. International Journal of Research Studies in Language Learning , 3 (7), 89-100.

Van Dijk, T. A. (2006). Discourse and manipulation. Discourse E society , 17 (3), 359-383.

Van Dijk, T. A. (2017). How Globo media manipulated the impeachment of Brazilian President Dilma Rousseff. Discourse $\&$ Communication , 11 (2), 199-229. https://doi.org/10.1177/1750481317691838

Goering, E., Connor, U. M., Nagelhout, E., \& Steinberg, R. (2011). Persuasion in fundraising letters: An interdisciplinary study. Nonprofit and voluntary sector quarterly , 40 (2), 228-246. doi: 10.1177/0899764009339216 